DOI: https://doi.org/10.47405/mjssh.v6i1.639

\begin{tabular}{|c|c|}
\hline$x_{10}$ & Malaysian Journal of Social Sciences and Humanities (MJSSH) \\
\hline Malaysian Journal of & Volume 6, Issue 1, January 2021 \\
\hline (MJ-SSH) & e-ISSN : 2504-8562 \\
\hline & $\begin{array}{l}\text { Journal home page: } \\
\text { www.msocialsciences.com }\end{array}$ \\
\hline
\end{tabular}

\title{
Hubungan antara Penggunaan Aplikasi Google Classroom Terhadap Pencapaian dalam Pembelajaran Sejarah
}

\author{
M. Kaviza ${ }^{1}$ \\ ${ }_{1}^{1}$ Pusat Pengajian Pendidikan dan Bahasa Moden, Universiti Utara Malaysia (UUM) \\ Correspondence: M. Kaviza (kavizakaviza@yahoo.com)
}

\begin{abstract}
Abstrak
Kajian berbentuk korelasi ini bertujuan untuk menentukan sama ada terdapat hubungan antara penggunaan aplikasi Google Classroom dari aspek pengetahuan, kemahiran dan sikap terhadap pencapaian dalam pembelajaran sejarah. Seramai 114 orang murid Tingkatan Empat yang dipilih berdasarkan teknik persampelan rawak mudah terlibat dalam kajian ini. Instrumen kajian ini merupakan soal selidik dan ujian pencapaian. Data kajian ini dianalisis secara statistik inferensi iaitu ujian Korelasi Pearson dan ujian Regresi Pelbagai melalui perisian IBM SPSS. Dapatan kajian ini menunjukkan bahawa terdapat hubungan linear positif yang sederhana tinggi secara signifikan antara min penggunaan aplikasi Google Classroom iaitu pengetahuan, kemahiran dan sikap terhadap pencapaian dalam pembelajaran sejarah. Selain itu, pengetahuan, kemahiran dan sikap dalam penggunaan aplikasi Google Classroom dilaporkan merupakan pembolehubah-pembolehubah peramal dan telah menyumbang sebanyak 27 peratus varians terhadap pencapaian dalam pembelajaran sejarah dalam kajian ini. Implikasi kajian ini telah memaparkan sumber maklumat kepada para guru sejarah untuk melaksanakan proses pembelajaran dan pemudahcaraan melalui penggunaan aplikasi Google Classroom dengan berkesan kerana aplikasi Google Classroom didapati mempengaruhi peningkatan pencapaian dalam pembelajaran sejarah dalam kalangan murid.
\end{abstract}

Kata kunci: aplikasi Google Classroom, pencapaian dalam pembelajaran sejarah, murid

\section{The Relationship between the Use of Google Classroom Application towards Achievement of Learning History}

\begin{abstract}
This correlation study aims to determine whether there is a relationship between the use of Google Classroom applications, in terms knowledge, skills and attitudes towards achievement in learning history. A total of 114 form four student's selected through simple random sampling techniques were involved in this study. This research instrument is a questionnaire and achievement test. The data of this study were analyzed statistically inferentially, such as Pearson Correlation test and Multiple Regression test through IBM SPSS software. The findings of this study indicated that there is a significant medium high positive linear relationship between the mean use of Google Classroom application, in terms knowledge, skills and attitudes towards achievement in learning history. In addition, knowledge, skills and attitudes in the use of Google Classroom applications are reported as predictor variables and have contributed 27 percent variance to the achievement in learning history in this study. The implications of this study provided information for the history teachers to implement the learning and facilitation process through the use of Google Classroom application effectively
\end{abstract}


because the Google Classroom application was influenced the improvement of achievement in history learning among students.

Keywords: Google Classroom application, achievement of history learning, student

\section{Pengenalan}

Perkembangan teknologi maklumat dan komunikasi telah menggalakkan perubahan dalam dunia pendidikan dengan membuat anjakan daripada proses pembelajaran secara tradisional kepada proses pembelajaran secara maya berasaskan teknologi dan internet (e-pembelajaran) yang dapat membentuk kolaborasi dan interaksi dua hala antara guru dan murid melalui pelaksanaan proses pembelajaran yang bermakna (Norfarahi, Mohd Isa \& Khadijah, 2020; Hapini et al., 2020). Sehubungan dengan itu, adalah tidak dinafikan bahawa mata pelajaran sejarah merupakan disiplin ilmu yang bersifat dinamik yang menekankan kepada proses pembelajaran sepanjang hayat dengan melaksanakan kepelbagaian strategi pembelajaran dan pemudahcaraan yang menjurus kepada pemupukan kemahiran berfikir aras tinggi dan pengaplikasian teknologi maklumat dan komunikasi bagi memenuhi matlamat dan aspirasi negara (Pusat Perkembangan Kurikulum [PPK], 2018; Kementerian Pendidikan Malaysia [KPM], 2013). Justeru, penggunaan media pembelajaran atas talian yang efektif dan interaktif dalam meningkatkan pencapaian dalam pembelajaran sejarah adalah disarankan dalam mewujudkan ruang persekitaran pembelajaran yang fleksibel dan menarik seiring dengan sifat dan kriteria murid-murid generasi alaf baru ini yang celik dengan teknologi.

Sehubungan dengan itu, penggunaan aplikasi Google Classroom sebagai media pembelajaran dalam mata pelajaran sejarah kini mula mendapat perhatian pada peringkat global dan nasional (Fitriningtiyas, Umamah \& Sumardi, 2019; Marharjono, 2020; Kaviza, 2020). Hal ini demikian kerana aplikasi Google Classroom merupakan platform pembelajaran percuma yang telah dibangunkan oleh pihak Google pada tahun 2014 untuk kegunaan guru-guru dalam melaksanakan proses pembelajaran dan pemudahcaraan atas talian yang menggabungkan elemen-elemen seperti email, dokumen, pembinaan dan penyimpanan bahan pembelajaran, penghantaran dan penggredan tugasan dan sebagainya (Hasnizar, Harwati \& Melor, 2019). Sungguhpun begitu, terdapat satu keperluan untuk menentukan sama ada penggunaan aplikasi Google Classroom dan pencapaian dalam pembelajaran sejarah saling mempengaruhi atau tidak. Hal ini disebabkan oleh pencapaian atau penguasaan murid dari segi pengetahuan, kemahiran dan nilai merupakan kayu ukur dalam meningkatkan kualiti dan mutu proses pembelajaran dan pemudahcaraan dalam mata pelajaran sejarah (PPK, 2018; Kaviza, 2019). Tambahan pula, dapatan kajian-kajian lepas telah melaporkan bahawa penggunaan aplikasi Google Classroom dapat meningkatkan pengetahuan, kualiti pembelajaran, kepuasan, kemahiran berfikir kritis dan kreatif dalam pelbagai disiplin ilmu lain (Miftah, Dwi \& Guntur, 2019; Bayarmaa \& Lee, 2018; Iftakhari, 2016; Hemrungrote \& Assawaboonme, 2017; Muhammad Japar, Dini \& Syifa, 2019) yang telah mencadangkan kepada pengkaji dalam kajian ini untuk mengenal pasti sama ada terdapat hubungan antara penggunaan aplikasi Google Classroom dan pencapaian dalam pembelajaran sejarah.

\section{Tujuan Kajian}

Kajian ini bertujuan untuk menentukan sama ada terdapat hubungan antara penggunaan aplikasi Google Classroom dari aspek pengetahuan, kemahiran dan sikap terhadap pencapaian dalam pembelajaran sejarah, disamping menentukan sama ada terdapat sumbangan pembolehubahpembolehubah peramal iaitu pengetahuan, kemahiran dan sikap dalam penggunaan aplikasi Google Classroom terhadap pencapaian dalam pembelajaran sejarah. 


\section{Objektif Kajian}

Objektif kajian ini ialah:

i. Menentukan sama ada terdapat hubungan yang signifikan antara penggunaan aplikasi Google Classroom dari aspek pengetahuan, kemahiran dan sikap terhadap pencapaian dalam pembelajaran sejarah

ii. Menentukan sama ada terdapat sumbangan yang signifikan bagi pembolehubahpembolehubah peramal iaitu pengetahuan, kemahiran dan sikap dalam penggunaan aplikasi Google Classroom terhadap pencapaian dalam pembelajaran sejarah.

\section{Persoalan Kajian}

Persoalan kajian ini ialah:

i. Adakah terdapat hubungan yang signifikan antara penggunaan aplikasi Google Classroom terhadap pencapaian dalam pembelajaran sejarah?

ii. Adakah terdapat hubungan yang signifikan antara pengetahuan dalam penggunaan aplikasi Google Classroom terhadap pencapaian dalam pembelajaran sejarah?

iii. Adakah terdapat hubungan yang signifikan antara kemahiran dalam penggunaan aplikasi Google Classroom terhadap pencapaian dalam pembelajaran sejarah?

iv. Adakah terdapat hubungan yang signifikan antara sikap dalam penggunaan aplikasi Google Classroom terhadap pencapaian dalam pembelajaran sejarah?

v. Adakah terdapat sumbangan yang signifikan bagi pembolehubah-pembolehubah peramal iaitu pengetahuan, kemahiran dan sikap dalam penggunaan aplikasi Google Classroom terhadap pencapaian dalam pembelajaran sejarah?

\section{Hipotesis Kajian}

Hipotesis kajian ini ialah:

$\mathrm{H}_{\mathrm{o} 1}$ : Tidak terdapat hubungan yang signifikan antara penggunaan aplikasi Google Classroom terhadap pencapaian dalam pembelajaran sejarah.

$\mathrm{H}_{\text {ola }}$ : Tidak terdapat hubungan yang signifikan antara pengetahuan dalam penggunaan aplikasi Google Classroom terhadap pencapaian dalam pembelajaran sejarah.

$\mathrm{H}_{\mathrm{olb}}$ : Tidak terdapat hubungan yang signifikan antara kemahiran dalam penggunaan aplikasi Google Classroom terhadap pencapaian dalam pembelajaran sejarah.

$\mathrm{H}_{\text {olc: }}$ : Tidak terdapat hubungan yang signifikan antara sikap dalam penggunaan aplikasi Google Classroom terhadap pencapaian dalam pembelajaran sejarah.

$\mathrm{H}_{\mathrm{o} 2}$ : Tidak terdapat sumbangan yang signifikan bagi pembolehubah-pembolehubah peramal iaitu pengetahuan, kemahiran dan sikap dalam penggunaan aplikasi Google Classroom terhadap pencapaian dalam pembelajaran sejarah.

\section{Metod Kajian}

Kajian ini dijalankan secara tinjauan yang menggunakan reka bentuk kajian korelasi (Cresswell, 2014) yang digunakan untuk menentukan hubungan antara dua pemboleh ubah iaitu pemboleh ubah bersandar dan pemboleh ubah tidak bersandar. Seramai 114 orang murid Tingkatan Empat 
DOI: https://doi.org/10.47405/mjssh.v6i1.639

berdasarkan teknik persampelan rawak mudah terlibat dalam kajian ini. Instrumen kajian ini terdiri daripada soal selidik dan ujian pencapaian. Kedua-dua instrumen tersebut telah disahkan oleh pakarpakar penilai dalam bidang pendidikan sejarah yang berpengalaman serta mempunyai nilai kebolehpercayaan Alfa Cronbach iaitu 0.95 bagi soal selidik skala likert lima mata dan Kuder Richardson iaitu 0.93, indeks diskriminasi dan indeks kesukaran bagi ujian pencapaian berbentuk item objektif yang dianggap baik dan diterima bagi tujuan kajian ini (Nunnally \& Bernstein, 1994; Nitko \& Brookhart, 2011). Data kajian ini telah dianalisis dengan menggunakan perisian IBM SPSS iaitu secara statistik inferensi iaitu ujian korelasi Pearson dan Regresi Pelbagai. Interpretasi kekuatan korelasi dalam kajian ini telah dilakukan berdasarkan interpretasi daripada kajian Davies (1971) seperti yang ditunjukkan pada Jadual 1.

Jadual 1: Interpretasi Kekuatan Korelasi

\begin{tabular}{ll}
\hline Skor Min & Tahap \\
\hline $0.70-1.00$ & Amat tinggi \\
$0.50-0.69$ & Tinggi \\
$0.30-0.49$ & Sederhana tinggi \\
$0.10-0.29$ & Rendah \\
$0.00-0.09$ & Diabaikan \\
\hline
\end{tabular}

Sumber: Adaptasi daripada Davies, (1971)

\section{Dapatan Kajian}

\section{Hubungan yang signifikan antara penggunaan aplikasi Google Classroom terhadap pencapaian dalam pembelajaran sejarah}

Berdasarkan Jadual 2, hasil dapatan kajian telah melaporkan bahawa nilai keofisien korelasi Pearson antara min penggunaan aplikasi Google Classroom terhadap pencapaian dalam pembelajaran sejarah $[r=0.46, p=0.00]$ adalah signifikan. Oleh itu, terdapat korelasi linear positif yang sederhana tinggi secara signifikan antara min penggunaan aplikasi Google Classroom terhadap pencapaian dalam pembelajaran sejarah. Maka, $\mathrm{H}_{\mathrm{o} 1}$ telah berjaya ditolak. Justeru, dapat dirumuskan bahawa penggunaan aplikasi Google Classroom dan pencapaian dalam pembelajaran sejarah adalah saling berhubungan dan mempengaruhi dalam kajian ini. Perkara ini telah menerangkan bahawa sekiranya penggunaan aplikasi Google Classroom meningkat, maka pencapaian dalam pembelajaran sejarah juga akan meningkat dalam kalangan murid.

Jadual 2: Hubungan antara min penggunaan aplikasi Google Classroom terhadap pencapaian dalam pembelajaran sejarah

\begin{tabular}{llll}
\hline & $\begin{array}{l}\text { Pencapaian dalam } \\
\text { pembelajaran } \\
\text { sejarah }\end{array}$ & Kekuatan \\
\hline Penggunaan & Pearson Correlation & 0.46 & Sederhana tinggi \\
aplikasi Google & Sig & 0.00 & \\
Classroom & $\mathrm{N}$ & 114 & \\
\hline \multicolumn{2}{c}{ * Correlation } & is significant at the 0.01 level (2-tailed) &
\end{tabular}

\section{Hubungan yang signifikan antara pengetahuan dalam penggunaan aplikasi Google Classroom dengan pencapaian dalam pembelajaran sejarah}

Berdasarkan Jadual 3, hasil dapatan kajian telah melaporkan bahawa nilai koefisien korelasi Pearson antara min pengetahuan dalam penggunaan aplikasi Google Classroom terhadap pencapaian dalam pembelajaran sejarah $[r=0.47, p=0.00]$ adalah signifikan. Oleh itu, terdapat korelasi linear positif yang sederhana tinggi secara signifikan antara min pengetahuan dalam penggunaan aplikasi Google Classroom terhadap pencapaian dalam pembelajaran sejarah. Maka, $\mathrm{H}_{\mathrm{ola}}$ telah berjaya ditolak. Justeru, 
dapat dirumuskan bahawa pengetahuan dalam penggunaan aplikasi Google Classroom dan pencapaian dalam pembelajaran sejarah adalah saling berhubungan dan mempengaruhi dalam kajian ini. Perkara ini telah menerangkan bahawa sekiranya pengetahuan dalam penggunaan aplikasi Google Classroom meningkat, maka pencapaian dalam pembelajaran sejarah juga akan meningkat dalam kalangan murid.

Jadual 3: Hubungan antara min pengetahuan dalam penggunaan aplikasi Google Classroom terhadap pencapaian dalam pembelajaran sejarah

\begin{tabular}{llll}
\hline & & $\begin{array}{l}\text { Pencapaian dalam } \\
\text { pembelajaran sejarah }\end{array}$ & Kekuatan \\
\hline Pengetahuan & Pearson & 0.47 & Sederhana tinggi \\
& Correlation & 0.00 & \\
& Sig & 114 & \\
$\mathrm{~N}$ & & \\
\hline
\end{tabular}

** Correlation is significant at the 0.01 level (2-tailed)

\section{Hubungan yang signifikan antara kemahiran dalam penggunaan aplikasi Google Classroom terhadap pencapaian dalam pembelajaran sejarah}

Berdasarkan Jadual 4, hasil dapatan kajian telah melaporkan bahawa nilai koefisien korelasi Pearson antara min kemahiran dalam penggunaan aplikasi Google Classroom terhadap pencapaian dalam pembelajaran sejarah $[r=0.33, p=0.00]$ adalah signifikan. Oleh itu, terdapat korelasi linear positif yang sederhana tinggi secara signifikan antara min kemahiran dalam penggunaan aplikasi Google Classroom terhadap pencapaian dalam pembelajaran sejarah. Maka, $\mathrm{H}_{\mathrm{olb}}$ telah berjaya ditolak. Justeru, dapat dirumuskan bahawa kemahiran dalam penggunaan aplikasi Google Classroom dan pencapaian dalam pembelajaran sejarah adalah saling berhubungan dan mempengaruhi dalam kajian ini. Perkara ini telah menerangkan bahawa sekiranya kemahiran dalam penggunaan aplikasi Google Classroom meningkat, maka pencapaian dalam pembelajaran sejarah juga akan meningkat dalam kalangan murid.

Jadual 4: Hubungan antara min kemahiran dalam penggunaan aplikasi Google Classroom terhadap pencapaian dalam pembelajaran sejarah

\begin{tabular}{llll}
\hline & & Pencapaian dalam & Kekuatan \\
& & Pembelajaran sejarah & \\
\hline Kemahiran & Pearson & 0.33 & Sederhana tinggi \\
& Correlation & 0.00 & \\
Sig & 114 & \\
$\mathrm{~N}$ & & \\
\hline
\end{tabular}

** Correlation is significant at the 0.01 level (2-tailed)

\section{Hubungan yang signifikan antara sikap dalam penggunaan aplikasi Google Classroom terhadap pencapaian dalam pembelajaran sejarah}

Berdasarkan Jadual 5, hasil dapatan kajian telah melaporkan bahawa nilai koefisien korelasi Pearson antara min sikap dalam penggunaan aplikasi Google Classroom terhadap pencapaian dalam pembelajaran sejarah $[r=0.40, p=0.00]$ adalah signifikan. Oleh itu, terdapat korelasi linear positif yang sederhana tinggi secara signifikan antara min sikap dalam penggunaan aplikasi Google Classroom terhadap pencapaian dalam pembelajaran sejarah. Maka, $\mathrm{H}_{\mathrm{olc}}$ telah berjaya ditolak. Justeru, dapat dirumuskan bahawa sikap dalam penggunaan aplikasi Google Classroom dan pencapaian dalam pembelajaran sejarah adalah saling berhubungan dan mempengaruhi dalam kajian ini. Perkara ini telah menerangkan bahawa sekiranya sikap dalam penggunaan aplikasi Google Classroom meningkat, maka pencapaian dalam pembelajaran sejarah juga akan meningkat dalam kalangan murid. 
DOI: https://doi.org/10.47405/mjssh.v6i1.639

Jadual 5: Hubungan antara min kemahiran dalam penggunaan aplikasi Google Classroom dan pencapaian dalam pembelajaran sejarah

\begin{tabular}{llll} 
& & $\begin{array}{l}\text { Pencapaian dalam } \\
\text { Pembelajaran Sejarah }\end{array}$ & Kekuatan \\
\hline Sikap & Pearson & 0.40 & Sederhana tinggi \\
& Correlation & 0.00 & \\
& Sig & 114 & \\
$\mathrm{~N}$ & & \\
\hline
\end{tabular}

** Correlation is significant at the 0.01 level (2-tailed)

\section{Sumbangan pembolehubah-pembolehubah peramal iaitu pengetahuan, kemahiran dan sikap dalam penggunaan aplikasi Google Classroom terhadap pencapaian dalam pembelajaran sejarah}

Berdasarkan Jadual 6 dan 7 menunjukkan bahawa pembolehubah-pembolehubah peramal seperti pengetahuan, kemahiran dan sikap dalam penggunaan aplikasi Google Classroom adalah signifikan terhadap pencapaian dalam pembelajaran sejarah $[F(3,113)=13.30, p=0.00]$ dan menyumbang sebanyak 27 peratus varians terhadap pencapaian dalam pembelajaran sejarah $\left(r^{2}=0.27\right)$. Tambahan pula, ketiga-tiga pemboleh ubah peramal tersebut dilaporkan telah memberi sumbangan secara signifikan dengan pencapaian dalam pembelajaran sejarah berdasarkan nilai pemberat regresi piawai ( $\beta$ ) iaitu pemboleh ubah pengetahuan $(\beta=0.43, t=4.00, p=0.00)$ yang merupakan penyumbang yang tertinggi dan diikuti dengan pemboleh ubah sikap $(\beta=0.32, t=2.53, p=0.01)$ dan pemboleh ubah kemahiran $(\beta=0.20, t=1.38, p=0.01)$. Perkara ini telah menunjukkan bahawa nilai $(\beta)$ bagi setiap unit peningkatan dalam pemboleh ubah tidak bersandar adalah diikuti dengan peningkatan setiap unit dalam pemboleh ubah bersandar. Oleh itu, nilai pekali menunjukkan bahawa terdapat hubungan linear bagi model persamaan garis lurus bagi pencapaian dalam pembelajaran sejarah dengan pembolehubahpembolehubah peramal adalah seperti berikut:

di mana

$$
\begin{gathered}
\mathrm{Y}=\mathrm{A}+\mathrm{B}_{1 \mathrm{X} 1}+\mathrm{B}_{2 \mathrm{X} 2}+\mathrm{B}_{2 \times 3}+\mathrm{e} \\
{\left[\mathrm{Y}=1.21+0.54_{\mathrm{X} 1}+0.27_{\mathrm{X} 2}+0.41_{\mathrm{X} 3}+0.41\right]}
\end{gathered}
$$

$\mathrm{y}=$ pencapaian dalam pembelajaran sejarah

$\mathrm{A}=$ pemalar

$\mathrm{B}_{1}, \mathrm{~B}_{2}, \mathrm{~B}_{3}=$ pekali

$\mathrm{x} 1=$ pengetahuan

$\mathrm{x} 2=$ kemahiran

$\mathrm{x} 3=$ sikap

$\mathrm{e}=$ ralat kajian

Maka, $\mathrm{H}_{\mathrm{o} 2}$ telah berjaya ditolak. Justeru, dapat dirumuskan bahawa pembolehubah-pembolehubah iaitu pengetahuan, kemahiran dan sikap dalam penggunaan aplikasi Google Classroom merupakan pembolehubah-pembolehubah peramal yang telah menyumbang secara signifikan terhadap pencapaian dalam pembelajaran sejarah iaitu sebanyak 27 peratus varians dalam kajian ini.

Jadual 6: Analisis Varians Regresi Pelbagai

\begin{tabular}{llllll}
\hline Pembolehubah & $\begin{array}{l}\text { Jumlah kuasa } \\
\text { dua }\end{array}$ & $\boldsymbol{d} \boldsymbol{f}$ & $\begin{array}{l}\text { Min kuasa } \\
\text { dua }\end{array}$ & $\boldsymbol{F}$ & Sig. \\
\hline Regresi & 26.71 & 3 & 8.90 & 13.30 & 0.00 \\
Reja & 73.65 & 110 & 0.67 & & \\
Jumlah & 100.36 & 113 & & & \\
\hline
\end{tabular}


DOI: https://doi.org/10.47405/mjssh.v6i1.639

Jadual 7: Analisis Regresi Pelbagai Pencapaian Sejarah dengan pemboleh ubah peramal

\begin{tabular}{|c|c|c|c|c|c|}
\hline Pembolehubah & $\begin{array}{l}\text { Pekali tidak } \\
\text { piawai (B) }\end{array}$ & Ralat pekali & $\begin{array}{l}\text { Pekali } \\
\text { Piawai }(\beta)\end{array}$ & $t$ & Sig. \\
\hline Pemalar & 1.21 & 0.41 & & 2.92 & 0.04 \\
\hline Pengetahuan & 0.54 & 0.13 & 0.43 & 4.00 & 0.00 \\
\hline Kemahiran & 0.27 & 0.20 & 0.20 & 1.38 & 0.01 \\
\hline Sikap & 0.41 & 0.16 & 0.32 & 2.53 & 0.01 \\
\hline
\end{tabular}

\section{Perbincangan Kajian}

Dapatan kajian ini yang menunjukkan bahawa terdapat hubungan yang signifikan antara penggunaan aplikasi Google Classroom dari aspek pengetahuan, kemahiran dan sikap terhadap pencapaian dalam pembelajaran sejarah adalah konsisten dengan dapatan kajian Susanti (2015) yang telah melaporkan bahawa terdapat hubungan korelasi yang signifikan antara pembelajaran efektif dalam aplikasi Google Classroom dengan nilai belajar kognitif dalam mata pelajaran Biologi dan dapatan kajian Jeya dan Brandford (2019) yang telah melaporkan bahawa terdapat hubungan yang tidak linear secara signifikan antara persepsi murid terhadap aplikasi Google Classroom sebagai platform bagi proses pembelajaran mudah alih (Mobile Learning) walaupun murid-murid mempunyai atribut tingkah laku positif terhadap prestasi, sikap dan motivasi. Tambahan pula, dapatan kajian Erhan dan Okan (2011) yang telah menunjukkan bahawa terdapat hubungan antara pendedahan murid dengan teknologi dan pencapaian dalam sains dan matematik dan dapatan kajian Haggang (2019) juga telah melaporkan bahawa terdapat hubungan korelasi yang signifikan yang kuat antara pencapaian tatabahasa dan sikap melalui penggunaan aplikasi Google Classroom telah menyokong dapatan kajian ini secara tidak langsung. Hal ini demikian kerana aplikasi Google Classroom merupakan media atau platform pembelajaran yang berpotensi digunakan dalam mata pelajaran sejarah bagi memudahkan proses pelaksanaan pembelajaran dan pemudahcaraan yang dapat menjimatkan masa dan paperless melalui penggunaan Learning Management System (LMS) secara sistematik dan teratur (Fitriningtiyas, Umamah \& Sumardi, 2018; Marharjono, 2020; Muhammed, Wibawo \& Jan, 2019; Fauzan \& Fatkhul, 2019).

Selain itu, pemboleh ubah peramal iaitu pengetahuan, kemahiran dan sikap dalam penggunaan aplikasi Google Classroom yang telah dilaporkan menyumbang sebanyak 27 peratus varians terhadap pencapaian dalam pembelajaran sejarah dalam kajian ini adalah konsisten dengan dapatan kajian Kundharu et al (2018) yang telah melaporkan bahawa motivasi pencapaian merupakan penyumbang terbesar dalam pemahaman ayat efektif dalam teks deskriptif melalui aplikasi Google Classroom dan dapatan kajian Susanti (2015) yang turut telah melaporkan bahawa faktor hasil belajar kognitif didapati mempengaruhi pembelajaran efektif melalui aplikasi Google Classroom sebanyak 10.7 peratus. Dapatan-dapatan kajian Kundharu et al (2018) dan Susanti (2015) adalah bertepatan dengan dapatan kajian Abdullah (2019) yang telah membuktikan bahawa persekitaran pembelajaran melalui penggunaan aplikasi Google Classroom mempunyai persepsi penggunaan yang tertinggi dalam kalangan murid iaitu sebanyak 86.45 peratus dan terdapat perbezaan yang signifikan antara pencapaian akademik melalui penggunaan aplikasi Google Classroom yang telah menyokong dapatan kajian ini secara langsung mahupun secara tidak langsung. Oleh itu, penggunaan aplikasi Google Classroom memainkan peranan penting dalam menjana dan meningkatkan pencapaian akademik dalam kalangan murid melalui pelaksanaan proses pembelajaran dan pemudahcaraan yang kondusif dan efektif dalam mata pelajaran sejarah.

\section{Kesimpulan}

Kesimpulannya, kajian ini telah melaporkan bahawa terdapat hubungan yang signifikan antara penggunaan aplikasi Google Classroom terhadap pencapaian dalam pembelajaran sejarah. Oleh itu, semua pihak perlu memainkan peranan penting bagi memastikan penggunaan aplikasi Google Classroom dapat memberikan impak yang positif terhadap keberkesanan pelaksanaan proses dan hasil 
pembelajaran serta peningkatan pencapaian akademik secara berterusan dalam kalangan murid seiring dengan perubahan dalam sistem pendidikan Malaysia yang menyarankan kepada penerapan elemen teknologi maklumat dan pengaplikasian strategi pembelajaran abad ke-21.

\section{Rujukan}

Abdullah, A. (2019). Usability testing of Google Cloud applications: Students perspectives. Journal of Technology and Science Education, 9(3), 326-339.

Bayarmaa, N \& Lee, A. (2018). Study on the application of Google Classroom for problem based learning. Journal of the Korea Academia-Industrial, 19(7), 81-87.

Creswell, J.W. (2014). Educational research: Planning, conducting and evaluating quantitative and qualitative research. ( $4^{\text {th }}$ ed.). United States of America: Pearson New International Edition.

Erhan, D \& Okan, B. (2011). The relationship between students; exposure to technology and their achievement in science and math. Turkish Online Journal of Educational Technology, 10(3), 311317.

Fauzan \& Fatkhul, A. (2019). The effectiveness of Google Classroom media on the students' learning outcomes of Madrasah Ibtidaiyah Teacher Education Department. Al-IBTIDA: Jurnal Pendidikan Guru Mi, 6(2), 271-285.

Fitriningtiyas, D.A., Umamah \& Sumardi. (2018). Google Classroom: as a media of learning history. ICEGE: IOP Conferences Series Earth and Environmental Sciences, 243, 1-8.

Haggang, M.H. (2019). Using Google Classroom in enhancing communicative grammar. Use and attitudes of non-English specialized post graduates. European Scientific Journal, 15(1), 261-281.

Hapini Awang, Zahrin Mat Aji, Wan Rozaini Sheikh Osman, Erwani Kamaruddin, Abdul Razak F. Shahathe al-Mashhudani \& Shakirah Khamis. (2020). Cabaran dalam melaksanakan teknologi maklumat dan komunikasi: Analisis kes persekitaran pembelajaran maya - Frog serta strategi untuk melastarikan penggunaan Google Classroom dalam kalangan guru. Journal of Educational Research \& Indigeneous Studies, 1(1), 1-9.

Hasnizar Basri, Harwati Hashim \& Melor Md Yunus (2019). Using Google Apps as learning strategy to enhance ESL Writing. Creative Education, 10, 2649-2657.

Hemrungrote, S.P.J \& Assawaboonme, S. (2017). Deployment of Google Classroom to enhance SDL cognitive skills: a case study to introduction to information technology course. International Conference on digital Arts, Media and technology, 201-204.

Iftakhar, S. (2016). Google classroom: What works and how? Journal of Education and Social Sciences, 3, 12-18.

Jeya, A.K \& Brandford, W. (2019). Google Classroom for mobile learning in higher education: Modelling the initial perceptions of students. Education and Information Technology, 1-25.

Kaviza, M. (2019). Hubungan penerapan elemen kemahiran pemikiran sejarah dalam proses pengajaran dan pembelajaran terhadap pencapaian mata pelajaran sejarah dalam kalangan murid. Juku: Jurnal Kurikulum \& Pengajaran Asia Pasifik, 7(1), 30-38.

Kaviza, M. (2020). Kesediaan murid terhadap penggunaan aplikasi Google Classroom sebagai platform pembelajaran sejarah. Malaysian Journal Social Sciences and Humanities, 5(4), 108115.

Kementerian Pendidikan Malaysia. (2013). Pelan Pembangunan Pendidikan Malaysia 2013-2025. Putrajaya: Kementerian Pendidikan Malaysia.

Kundharu, S., Rosliana, I.P., Rio, D., Indry, M., I-Ketut, S, Siti, I., Wati, I \& Hespi, S. (2018). Relationship between effective sentence understanding and achievement motivation with descriptive text writing skill on Google Classroom. International Journal of Engineering \& Technology, 7(213), 432-436.

Marharjono (2020). Manfaat pembelajaran sejarah menggunakan Google Classroom pada masa pandemic Covid-19. Ideaguru: Jurnal Karya Ilmiah Guru, 5(1), 56- 63.

Miftah, N.S., Dwi, S., \& Guntur, M. (2019). Effects of Cooperative blended learning using Google Classroom on critical thinking skills. Advances in Social Sciences, Education and Humanities Research, 349, 326-330.

Muhammad Japar, Dini Nur Fadhillah \& Syifa Syarifa. (2019). Civic Education through E-Learning in higher education. Advances in Social Sciences and Humanities, 335, 505-511. 
DOI: https://doi.org/10.47405/mjssh.v6i1.639

Muhammed, L.H., Wibawo, H.P \& Jan, W. (2019). Pre-service students' teachers perception of using Google Classroom in a blended course. Humanities and Social Sciences Review, 7(2), 363-368.

Nitko, A.J. \& Brookhart, S.M. (2011). Educational Assessment of students ( ${ }^{\text {th }}$ ed.). New York: Pearson Ltd.

Norafarahi Zulkifli, Mohd Isa Hamzah \& Khadijah Abdul Razak. (2020). Isu dan cabaran penggunaan MOOC dalam proses pengajaran dan pembelajaran. Journal of Research, Policy \& Practice of Teachers \& Teacher Education, 10(1), 77-94.

Nunnally, J.C., \& Bernstein, I.H. (1994). Psychometric theory (3 ${ }^{\text {rd }}$ ed.). New York: McGraw Hill.

Pusat Perkembangan Kurikulum. (2018). Dokumen Standard Kurikulum dan Pentaksiran Sejarah Tingkatan 4 dan 5. Putrajaya: Kementerian Pendidikan Malaysia.

Susanti, L. (2015). Hubungan penggunaan Google Classroom sebagai pembelajaran efektif dan paperless terhadap nilai hasil belajar kognitif pada mata pelajaran biologi di SMA Charis Malang. Inovasi Pendidikan di Era Big Data dan Aspek Psikologinya II, 253-258. 